\title{
Estudo da biologia molecular do Schistosoma mansoni.
}

\author{
Ricardo De Marco
}

Documento apresentado ao Instituto de Física de São Carlos, como parte das exigências para obtenção do titulo de livre-docente.

Agosto de 2015 

Dedico este trabalho a Cristiane, Akira e Kenji. 



\section{Agradecimentos}

Aos meus ex-orientadores professores Sergio Verjovski-Almeida e R. Alan Wilson pelos ensinamentos e colaboração.

A professora Ana Paula U. Araujo pelo o constante auxilio que me prestou desde os meus primeiros dias no IFSC

A todos os membros do grupo de Biofísica do IFSC pelo apoio e companheirismo.

Aos minhas alunas Ana Eliza, Ana Felizartti, Camila, Daniele, Débora, Gisele e Natália por confiarem em mim para ajudá-las a desenvolver seus projetos.

As técnicas do grupo de Biofísica, Bel e Andressa, pela constante ajuda com os alunos e com a os diversos assuntos do dia a dia do laboratório.

Ao Prof. Richard C. Garratt e Dr. Humberto Pereira pela colaboração nas linhas de pesquisa que desenvolvemos em conjunto.

A todo corpo administrativo do IFSC pelo suporte.

A FAPESP, CNPq e CAPESP pelo suporte financeiro que permitiu o desenvolvimento da minha linha de pesquisa. 

Índice

Introdução $\quad 9$

Referências 11

Capitulo 1- Estudo de proteínas codificadas por Genes de Micro-Exon (MEGs) na interface parasito-hospedeiro na esquistossomose. 12

1.1- A estudo da relação parasito-hospedeiro na esqusitossomose. 12

1.2-O tegumento do Schistosoma mansoni. 13

1.3-O esôfago e a glândula do esôfago S. mansoni.

1.4-Genes de Micro-Exons 16

1.5- Evolução da sequência codificante de MEGs e outros genes codificando proteínas expostas pelo parasito no hospedeiro definitivo. 20

$\begin{array}{ll}\text { Considerações finais (Capitulo 1) } & 21\end{array}$

Contribuições do candidato ao tema (Capitulo 1). 22

Referências. (Capitulo 1)

Capítulo 2- Estudo da dinâmica e papel septinas em Schistosoma mansoni. 26

2.1- O estudo de proteínas de citoesqueleto em Schistosoma. 26

2.2- Septinas $\quad 27$

2.3-Septinas em Schistosoma mansoni $\quad 29$

Considerações finais (Capítulo 2) 31

Contribuições do candidato ao tema (Capitulo 2). 32

Referências (Capitulo 2).

Capítulo 3- estudo da estrutura genômica de S. mansoni e sua evolução. 35

3.1- A estrutura do genoma de Schistosoma mansoni. 35

3.2-Elementos de transposição e sua dinâmica em S. mansoni. 35

3.3- Evolução da estrutura de genes de micro-exon (MEGs) em schistosomas 38

Considerações finais (Capitulo 3). 39

Contribuições do candidato ao tema (Capitulo 3). 39

Referências (Capitulo 3). 


\section{Introdução}

Schistosoma mansoni é um platelminto parasitário, sendo um dos principais agente etiológicos da esquistossomose em humanos. Das espécies que parasitam seres humanos, somente o $S$. mansoni existe na América, mas este também pode ser encontrado na África e no Oriente Médio. As outras principais espécies são Schistosoma haematobium, que se concentra em países da África e Leste do Mediterrâneo, e Schistosoma japonicum, que se concentra no Sudeste Asiático e no Pacífico Ocidental. A esquistossomose constitui hoje um grave problema de saúde pública em vários países tropicais. A doença foi reportada em 78 países e pode ser considerada endêmica em 52 deles (WHO, 2014). Estima-se que em 2003 existiam 207 milhões de pessoas infectadas e 779 milhões de pessoas em risco (Steinmann, 2006). Em 2012, pelo menos 249 milhões de pessoas estavam em regiões endêmicas, para as quais era recomendado o emprego de tratamento preventivo (WHO, 2014).

O Praziquantel é a única droga efetivamente utilizada no combate a esquistossomose devido a sua eficácia, segurança, conveniência operacional e preço (Cioli et al., 2014). No entanto, é preocupante o fato que isolados resistentes ao medicamento já foram descritos (Ismail et al., 1996; Liang et al., 2001) e se pressupõe que a existência de cepas resistentes ou tolerantes à droga seja o motivo para a baixa taxa de cura de pacientes no Senegal (Danso-Appiah and De Vlas, 2002). Além disso, o uso do Praziquantel não impede a reinfecção dos pacientes, razão pela qual o desenvolvimento de uma vacina é considerado uma prioridade.

O parasita tem um ciclo de vida complexo que alterna a passagem por dois hospedeiros e formas intermediárias de vida livre (figura 1). A infecção em humanos é iniciada pela penetração de cercárias na pele. A forma adulta tem como hospedeiro definitivo o homem e encontra condições favoráveis para seu desenvolvimento no sistema porta intra-hepático. Ao contrário do encontrado na maioria dos platelmintos, os vermes adultos de Schistosoma são dióicos (Loker e Brant, 2006). A fêmea adulta é delgada e mais longa que o macho e encontra-se protegida dentro do canal ginecóforo do macho. O pareamento entre macho e fêmea fornece estímulos necessários ao desenvolvimento sexual das fêmeas. Quando se acasalam, os vermes vão para as veias do intestino, onde a fêmea pode produzir até 3 mil ovos por dia. 


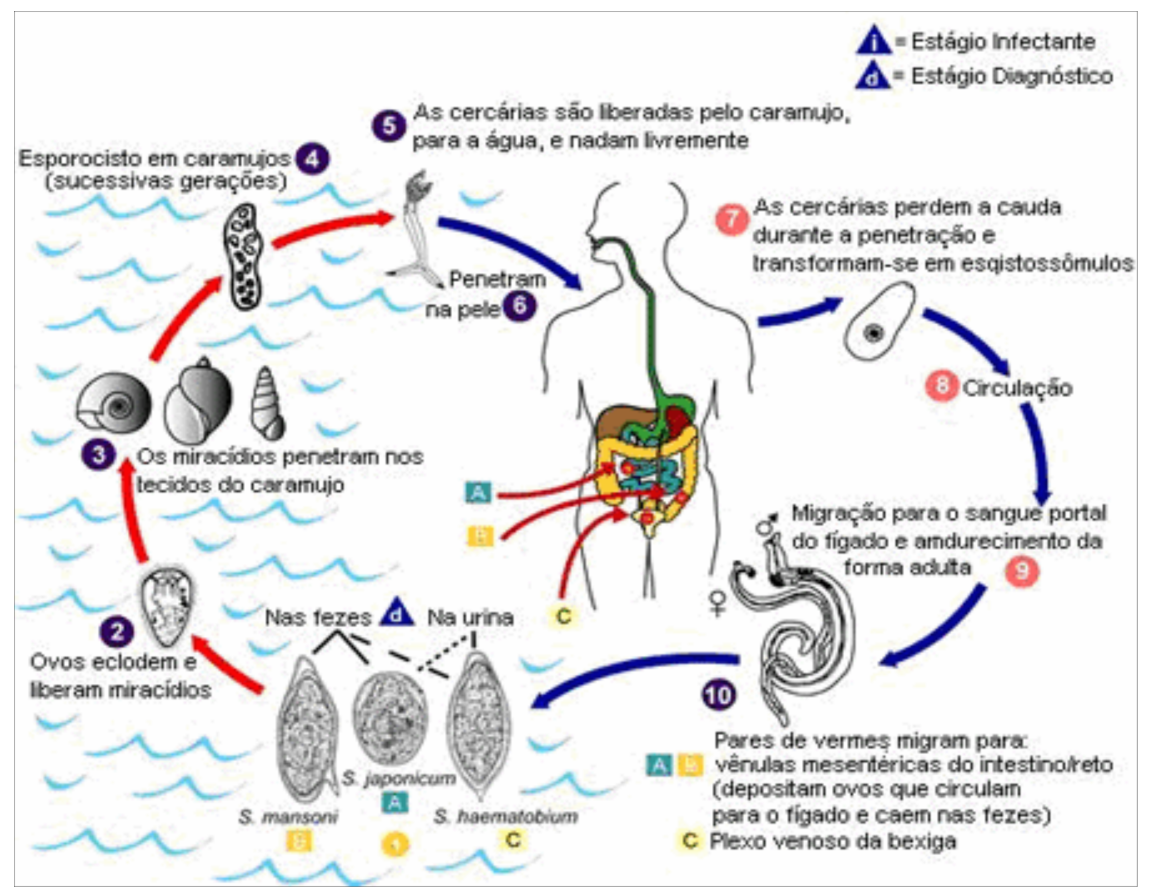

Figura 1- O ciclo de vida do Schistosoma. (modificado de CDC, http://www.dpd.cdc.gov/dpdx/HTML/Schistosomiasis.htm)

Devido a complexidade de seu ciclo de vida, é esperado que o parasito apresente diversas modificações em seu metabolismo, sendo observado que uma série de genes são transcritos de forma específica ao longo do ciclo de vida (Verjovski-Almeida et al., 2003). O estudo da biologia molecular deste organismo é peça fundamental para o melhor entendimento dos mecanismo associados ao parasitismo que permitirão o desenvolvimento de novas terapias.

O recente sequenciamento do genoma e transcriptoma de diversas especies de Schistosoma abriram oportunidade para um estudo mais detalhados dos mecanismos moleculares associados ao ciclo de vida do parasito. Conforme descrito nos capítulos abaixo, nosso grupo vem utilizando esta oportunidade de diferentes formas. Uma delas é o estudo da interação do do parasito com o hospedeiro definitivo através do estudo de uma classe de genes denominada genes de micro-exon (MEGs), que apresenta um intricado mecanismo genético para produção de proteínas variantes. Outra abordagem envolve a caracterização de Septinas que são proteínas de citoesqueleto que não foram previamente estudadas em platelmintos e que podem contribuir no entendimento de uma serie de processos celulares do parasito. Finalmente, estudo bioinformáticos do genoma de $S$. mansoni vem nos permitindo caracterizar sua estrutura e evolução. 


\section{Referências (Introdução)}

Cioli D, Pica-Mattoccia L, Basso A, Guidi A. Schistosomiasis control: praziquantel forever? Mol Biochem Parasitol. 2014; 195(1):23-9.

Danso-Appiah A, De Vlas SJ. Interpreting low praziquantel cure rates of Schistosoma mansoni infections in Senegal. Trends Parasitol. 2002; 18(3):125-9.

Ismail M, Metwally A, Farghaly A, Bruce J, Tao LF, Bennett JL. Characterization of isolates of Schistosoma mansoni from Egyptian villagers that tolerate high doses of praziquantel. Am J Trop Med Hyg. 1996; 55(2):214-8.

Liang YS, Coles GC, Dai JR, Zhu YC, Doenhoff MJ. Biological characteristics of praziquantelresistant and -susceptible isolates of Schistosoma mansoni. Ann Trop Med Parasitol. 2001; 95(7):71523.

Loker ES, Brant SV. Diversification, dioecy and dimorphism in schistosomes. Trends Parasitol. 2006; 22(11):521-8.

Steinmann P, Keiser J, Bos R, Tanner M, Utzinger J. Schistosomiasis and water resources development: systematic review, meta-analysis, and estimates of people at risk. Lancet Infect Dis. 2006; 6(7):411-25.

Verjovski-Almeida S, DeMarco R, Martins EA, Guimarães PE, Ojopi EP, Paquola AC, Piazza JP, Nishiyama MY Jr, Kitajima JP, Adamson RE, Ashton PD, Bonaldo MF, Coulson PS, Dillon GP, Farias LP, Gregorio SP, Ho PL, Leite RA, Malaquias LC, Marques RC, Miyasato PA, Nascimento AL, Ohlweiler FP, Reis EM, Ribeiro MA, Sá RG, Stukart GC, Soares MB, Gargioni C, Kawano T, Rodrigues V, Madeira AM, Wilson RA, Menck CF, Setubal JC, Leite LC, Dias-Neto E. Transcriptome analysis of the acoelomate human parasite Schistosoma mansoni. Nat Genet. 2003; 35(2):148-57.

WHO, Fact sheet number 155, 2014. 


\section{Capitulo 1- Estudo de proteínas codificadas por Genes de Micro-Exon (MEGs) na interface parasito-hospedeiro na esquistossomose.}

\section{1- A estudo da relação parasito-hospedeiro na esqusitossomose.}

Uma vez instalado no hospedeiro definitivo, o verme adulto de Schistosoma é capaz de sobreviver por décadas. A maioria de indivíduos infectados não apresentam manifestações severas da doença e a principal manifestação de patologia é associada a resposta imune à ovos depositados no fígado e intestino e não aos vermes adultos (Jenkins et al., 2005). Ainda não é conhecido qual é o mecanismo que permite com que o parasito sobreviva durante décadas, apesar de estar constantemente exposto ao sistema imune do hospedeiro (Colley e Secor, 2014).

Uma possível estratégia de escape seria através da modulação de respostas do sistema imune com a utilização de fatores secretados pelo parasito. Já foi demonstrado que a exposição do sistema imune à secreções de ovos e esquistossômulos leva a ativação de diversas vias sinalizadoras do sistema imune, produzindo respostas que poderiam ser favoráveis ao desenvolvimento e manutenção da infeção. No entanto, o conhecimento do conteúdo das secreções que levariam a tais respostas ainda é incompleto (Jenkins et al., 2005).

Outro possível mecanismo de escape do hospedeiro proposto foi o chamado mimetismo molecular, onde a expressão de moléculas semelhantes a aquelas existentes no hospedeiro permitiriam que o parasita interferisse no sistema imune do hospedeiro e escapasse da detecção pelo mesmo (Salzet et al., 2000). Em vários casos sugeriu-se a aquisição de genes do hospedeiro através do fenômeno de transferência horizontal, como para o gene de albumina (Williams et al., 2006), de fatores de histocompatibilidade (Iwamura et al., 1995) e o gene de uma proteína inibidora de complemento denominada CRIT (Inal, 2005). No entanto, tais eventos de transferência horizontal foram contestados, baseados no fato que não foi possível encontrar as sequências relativas aos genes de albumina e do fator de histocompatibilidade na montagem do genoma de $S$. mansoni e nem a sequência do gene de CRIT na sequência do genoma humano. Desta maneira, foi proposto que as demonstrações de transferência horizontal resultavam de contaminações em reações de PCR (DeMarco et al., 2007*).

* Contribuição do candidato ao tema. 
Foi também proposto que escape do sistema imune poderia ser facilitado através da aquisição direta de proteínas do hospedeiro, já tendo sido demonstrado a aquisição de antígenos de tipagem sanguínea (Goldring et al., 1976), Receptores Fc (Loukas et al., 2001), imunoglobulinas e proteínas de complemento (Braschi e Wilson, 2006), entre outros através da detecção dos mesmo na superfície do parasito. Tais dados sugerem um mecanismo específico de aquisição destes fatores, para qual não existem evidências até o momento.

É possível notar que, apesar de existirem várias propostas para explicar a capacidade do $S$. mansoni de sobreviver no hospedeiro definitivo, ainda há grandes lacunas nos mecanismos moleculares subjacentes. Portanto, somente o estudo molecular das interfaces e secreções do parasito permitirão o desenvolvimento de propostas mais explícitas de como certos fenômenos são mediados.

\section{2-O tegumento do Schistosoma mansoni.}

O tegumento consiste em um sincício citoplasmático encapsulado por duas membranas tegumentais que revestem a superfície do parasita (figura 2). Os principais tipos de inclusões membranosas presentes no tegumento são mitocôndrias, vesículas multilamelares e corpos discoides. O sincício anuclear está ligado às células subtegumentais via conexões citoplasmáticas, visto que as celulas subtegumentais se encontram abaixo de uma camada muscular. Nestas células ocorre a síntese dos corpos discoides e vesículas multilamelares quer são posteriormente transportadas para o sincício (Abath and Werkhauser,1996, Braschi et al., 2006). A superfície do tegumento é formada pela membrana plasmática sobreposta por uma segunda bicamada lipídica, denominada membranocalix. O tegumento é formado logo após a penetração do parasito através da pele do hospedeiro vertebrado; o esquistossômulo começa a se desenvolver e o processo de origem do tegumento inicia-se a partir da fusão de vesículas multilamelares, produzidas nas células sub-tegumentais, na superfície do parasito (Skelly e Wilson 2006). Supõem-se que o membranocalix se mantém devido da fusão de vesícula multilamelares a membrana plasmática na base do fossos tegumentais (Wilson, 2012).

O tegumento foi alvo de vários estudos proteômicos (VanBalkom et al., 2005; Braschi et al., 2006; Braschi and Wilson 2006) que permitiram uma descrição das proteínas mais abundantes deste 
tecido. Estudos de proteômicos utilizando biotinilação de proteínas expostas na superfície do parasita permitiu a identificação de 28 proteínas (Braschi e Wilson, 2006). Deve-se notar, no entanto, que a marcação de tais proteínas foi realizada com um reagente de baixo peso molecular e pressupõe-se que grande parte das proteínas detectadas neste ensaio estaria na verdade abaixo da membrana mais externa do tegumento, o membranocalix, que funcionaria como uma barreira física contra o reconhecimento da maioria destas proteínas pelo sistema imune (Braschi e Wilson 2006). Além disso, foi demonstrado que parasitas sob ação de drogas que causam distúrbios no tegumento, como o praziquantel, apresentam sensibilidade maior a soros imunes (Fallon et al., 1996), fornecendo maior evidencia sobre a ação protetiva do mesmo.

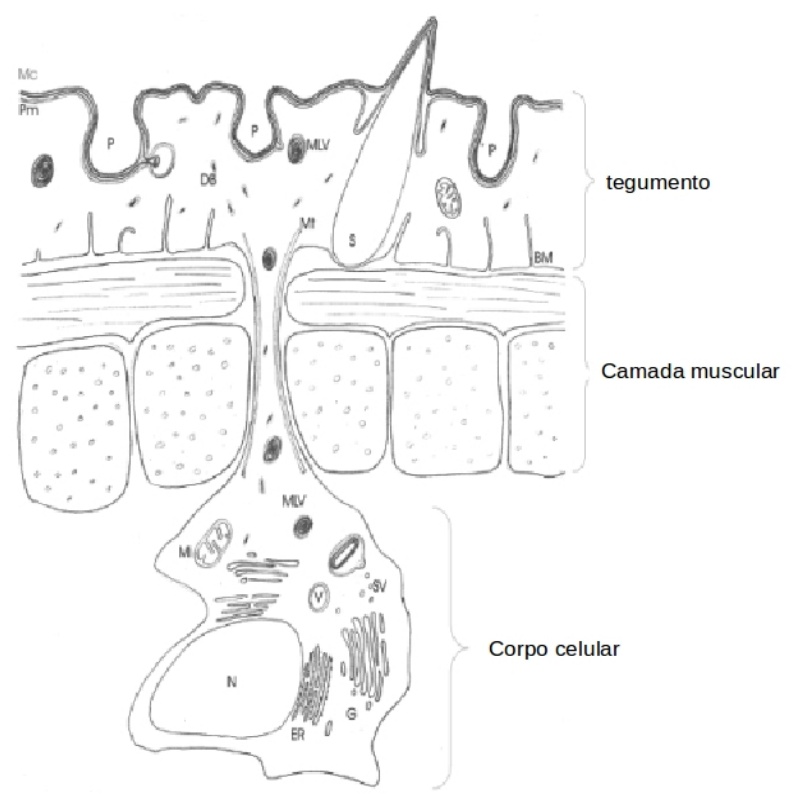

Figura 2- Representação diagramática do tegumento do Schistosoma mansoni (Adaptado de Braschi et al., 2006). BM: membrana basal. DB: corpo discóide. ER: retículo endoplasmático. G: aparato de Golgi. Mc: membranocalix. Mi: mitocôndria. MLV: vesícula multilamelar. Mt: microtúbulo. N: Núcleo. P; fosso. Pm: membrana plasmática. S: espinha. SV: vesículas secretoras. V: vacúolo.

O tegumento tem papel ativo na alimentação do parasita, absorvendo glicose do sangue do hospedeiro através de dois transportadores (Skelly e Shoemaker, 1996), e aminoácidos via um transportador que se localiza na membrana externa do tegumento (Skelly et al., 1999). Devido a esta 
absorção de nutrientes pelo tegumento, o Schistosoma pode sobreviver sem um intestino funcional por um prolongado período de tempo (Popiel and Basch, 1984). Além disso três enzimas hidrolíticas de fosfato em moléculas orgânicas foram detectadas na superfície do tegumento: a Apirase, a Fosfodiesterase e a Fosfatase alcalina (DeMarco et al., 2003; Braschi and Wilson 2006). Isso permitiu levantar a hipótese de que tais enzimas tenham a função remover grupos fosfato para permitir a passagem destes compostos pela membrana plasmática conforme observado em outros organismos e assim contribuir com a aquisição destes compostos (Braschi et al., 2006).

Devido a possível exposição direta ao sistema imune do parasito, duas proteínas tegumentais expostas foram propostas como candidatas vacinais. A proteína Sm 29 é uma proteína solúvel e supõem-se que a mesma possa se localizar entre a membrana plasmática e o membranocalix (Braschi e Wilson 2006). Testes vacinais com esta proteína resultaram em 51\% de redução da carga parasitária (Cardoso et al., 2008). A proteína TSP-2 é uma tetraspanina localizada no tegumento provavelmente ancorada na membrana plasmática (Braschi e Wilson 2006). Ensaios vacinais com este antígeno resultaram em redução de 57\% da carga parasitária (Tran et al., 2006). No entanto, um alto grau de polimorfismo foi encontrado para esta proteína o que poderia limitar seu valor como candidato vacinal (Zhang et al., 2011).

\section{3-O esôfago e a glândula esofágica $S$. mansoni.}

O sistema digestório de S. mansoni é constituído por um sugador oral, esôfago e estômago (Figueredo et al., 2015). Na fase adulta o parasita se alimenta de grandes quantidades de sangue, estimando-se que 39.000 e 330.000 eritrócitos sejam ingeridos por hora por vermes adultos machos e fêmeas, respectivamente (Lawrence, 1973). O processamento do sangue ingerido inicia-se no esôfago, onde os eritrócitos são rapidamente lisados (Hall et al., 2011). No estômago diversas peptidases das classes cisteína e aspártico são responsáveis pela digestão da hemoglobina proveniente dos eritrócitos (Caffrey et al., 2004).

É possível separar o esôfago de Schistosoma em duas porções, a anterior e a posterior (Figura 3). Já foi descrito que a porção anterior do esôfago de $S$. mansoni e S.japonicum também possuem uma estrutura sincicial na forma de projeções citoplasmáticas em direção ao lúmen do esôfago. Esta 
estrutura sincicial é conectada a uma aglomeração de aproximadamente 700 células enriquecidas em retículo endoplásmatico rugoso e complexo de Golgi (Li et al., 2013*; Li et al. 2014).

Na porção posterior do esôfago, também denominada glândula esofágica, observa-se também uma estrutura sincicial que possui projeções citoplasmática bastantes finas, formando placas que aumentam a superfície luminal deste tecido em aproximadamente 26 vezes. Este tecido possui aproximadamente 1.000 células em machos de S. mansoni localizadas abaixo da camada muscular e conectadas ao sincício através de canais recoberto por microtúbulos (Li et al., 2013*).

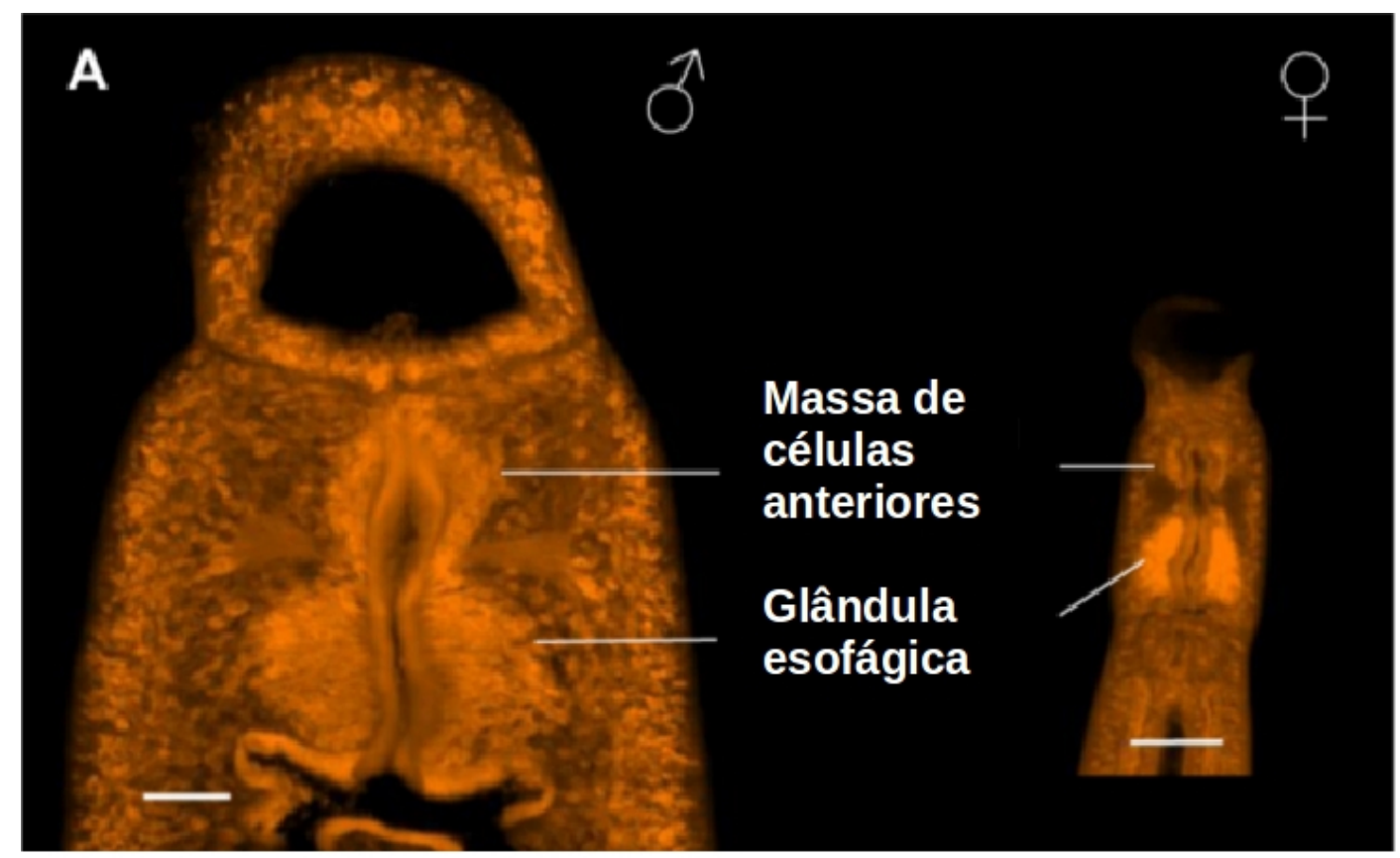

Figura 3- Imagem do esôfago de vermes adultos de Schistosoma macho e fêmea. Imagens foram produzidas a partir de vermes corados com o corante Carmim de Langeron através de microscopia confocal. A indicação "Massa de célula anteriores ” aponta o agrupamento de células circundando a porção anterior do esôfago. A indicação “Glândula esofágica” aponta a glândula esofágica localizada na região posterior do esôfago. Adaptado de Li et al., 2013.

\section{4-Genes de Micro-Exons}

Micro-exons são exons muito curtos, cuja a presença já foi descrita em um número limitado de genes de vários organismos (variando de 0.5 to $1.6 \%$ do total de genes de um organismo). No entanto, praticamente todos os genes nos quais a presença de micro-exons foi descrita apresentavam apenas

* Artigo do candidato no tema. 
somente um exon deste tipo (Volfovsky et al., 2003). Uma estrutura gênica contendo múltiplos microexons foi descrita para o gene do antígeno 10.3 de S. mansoni onde exons de 27 pares de bases constituíam um elemento repetitivo de 81 pares de bases encontrados em tandem em uma porção deste gene (Davis et al., 1988).

O mapeamento de transcritos existentes em bases públicas no genoma do $S$. mansoni possibilitou a dedução da estrutura de um grupo de 18 famílias de genes que também distinguiam pelo fato de possuírem vários micro-exons (Berriman et al., 2009*, DeMarco et al., 2010*), posteriormente o sequenciamento do transcriptoma com a tecnologia de RNA-Seq permitiu a dedução de 7 novas famílias com tais características (Almeida et al., 2011*). Estes genes foram denominados “Micro-Exon Genes (MEGs)” e possuem em comum as seguintes características (Figura 4): presença de vários micro-exons (<36bp) que compõem em media 75\% das sequências codificantes; alta proporção (92\%) de exons internos simétricos; presença de exons longos flanqueadores onde estão contidos os UTRs do transcritos e porções codificantes para o peptídeo sinal ou hélice transmembrana (Berriman et al., 2009*, DeMarco et al., 2010*).

A proporção de exons simétricos muito maior do que seria esperada por acaso, indica uma pressão evolutiva para manutenção desta característica. Isso permitiria a realização de eventos de splicing alternativo onde a retirada de algum destes exons do transcrito maduro não resultaria na mudança no quadro de leitura do transcrito. De fato, o sequenciamento de produtos de RT-PCR utilizando primers específicos para algumas MEGs demonstraram a existência diversas forma de splicing alternativo, nas quais ocorria a omissão de alguns micro-exons (DeMarco et al., 2010*).

Todas as MEGs codificam proteínas que não têm similaridade com nenhuma proteína de organismos fora do gênero Schistostoma, indicando uma origem recente destas proteínas e com funções bastante específicas. Além disso, experimentos de microarray indicaram que a expressão da maioria das MEGs tende a aumentar quando o parasito invade o hospedeiro humano. Deste modo, é possível levantar a hipótese que as MEGs codificam proteínas envolvidas na interação do parasita com o hospedeiro definitivo (DeMarco et al., 2010*).

* Artigo do candidato no tema. 


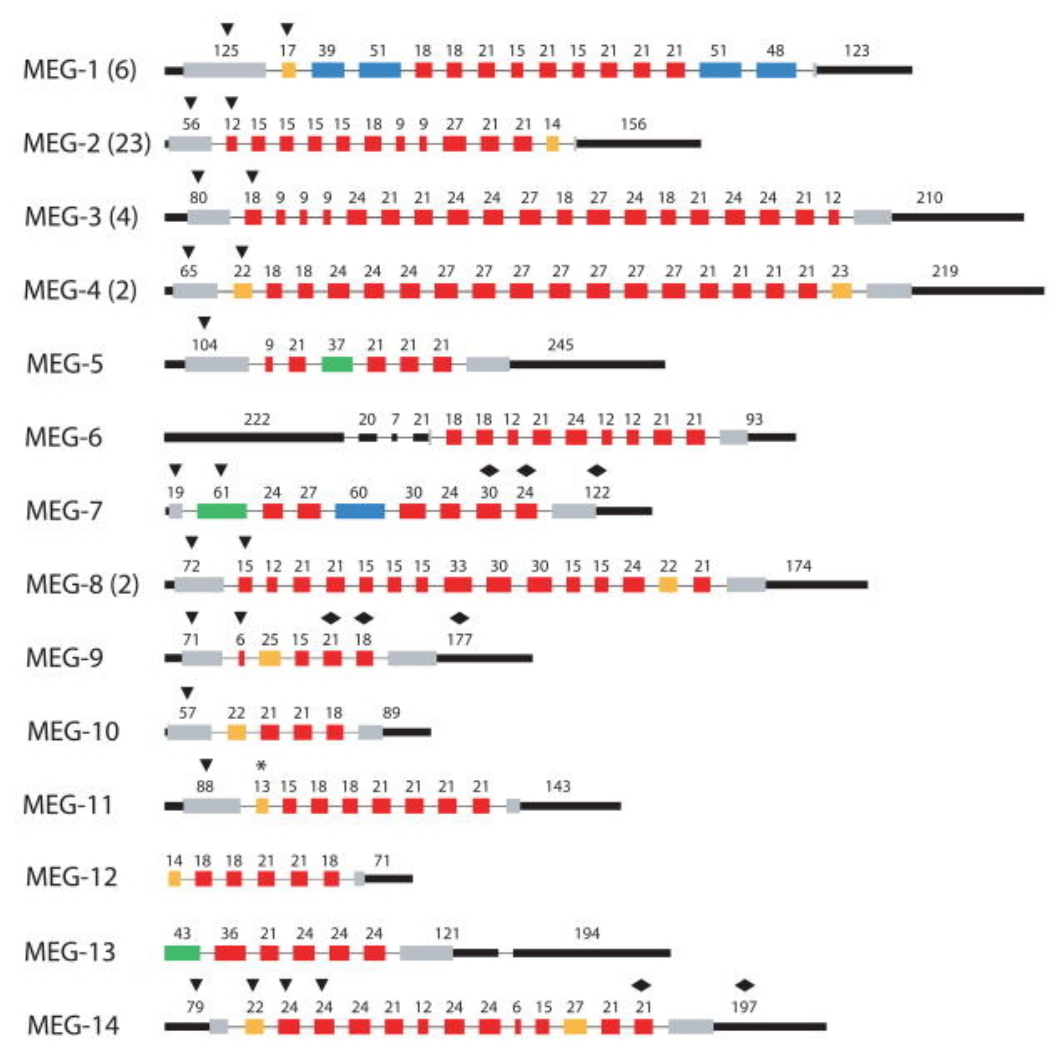

Figura 4- representação esquemática de MEGs em Schistosoma mansoni. A estrutura de cada MEG é representada com retângulos indicando exons e linhas finas representando introns. Linhas grossas nas extremidades representam regiões UTRs. O numero acima de cada exon representa seu comprimento. Retângulos em vermelho representam micro-exons (tamanho <36 bp) simétricos. Retângulos em laranja representam micro-exons não simétricos. Retângulos em azul representam exons de tamanho normal e simétricos. Retângulos em verde representam exons de tamanho normal e não simétricos. Retângulos cinzas representam a região codificante de exons flanqueadores. Exons com triângulos acima codificam para peptídeo sinal e com losango codificam para transmembranas (Retirado de Berriman et al., 2009).

Esta hipótese é reforçada pelo fato que praticamente todas as proteínas codificadas por genes de micro-exon possuem um peptídeo sinal previsto em sua sequência, sugerindo que são secretadas (DeMarco et al., 2010*). Experimentos proteômicos utilizando secreções detectaram produtos proteicos proveniente de genes de duas famílias de MEGs em experimentos com secreções de ovos (MEG-2 e -3) e uma família em secreções de esquistossômulo (MEG-3). Interessantemente, nos géis bidimensionais produzidos em tais experimentos cada um dos genes destas famílias possuía correspondência com vários pontos de diferentes pontos isoelétricos e massas moleculares na identificação de peptídios

* Artigo do candidato ao tema. 
trípticos via espectrometria de massas. Isso forneceu evidencia adicional que cada gene produziria diversas proteínas diferentes devido ao fenômeno de splicing alternativo (DeMarco et al., 2010*).

Experimentos de imunolocalização e de Whole-mount In Situ Hybridization (WISH) permitiram a associação das proteínas MEG-14, -4.1 e 4.2, com o aparelho digestivo primordial em cercária e com a glândula do esôfago do parasita em vermes adultos, e da proteína MEG-3.2 à glândula da cabeça de esquistossomulos (DeMarco et al., 2010*:Li et al., 2013*). Além disso, a proteína MEG-5 foi detectada em preparações da membrana do tegumento de vermes adultos através de ensaios proteômicos (DeMarco et al., 2010*). Desta maneira, é possível notar a associação de MEGs a órgãos secretórios que estão localizados na interface parasito-hospedeiro.

Já foram realizados alguns experimentos utilizando a expressão de MEGs em sistema recombinante. O domínio hidrofílico da proteína MEG-14, referente a isoforma mais frequente, foi expresso em sistema bacteriano e a análise de sua estrutura através da técnica de dicroísmo circular utilizando radiação sincrotron (SRCD) demonstrou que a mesma possui um espectro típico de proteína sem estruturas secundárias regulares. No entanto foi observado que ocorria uma transição de uma estado desordenado para um ordenado como consequência de fatores externos como temperatura, polaridade do solvente, carga de moléculas parceiras ou desidratação (Lopes et al., 2013*). Tal comportamento é característico de proteínas intrinsecamente desordenadas, sendo que esta classe de proteínas já foram descritas envolvidas em interações proteicas com múltiplos parceiros, acompanhada de um aumento na organização da proteína desordenada (Uversky, 2011) . A presença de uma proteína deste tipo exposta na superfície da glândula esofágica do parasito sugere que possivelmente ocorre interação entre esta proteína com outras MEGs ou com proteínas do hospedeiro definitivo.

Outra proteína expressa em sistema recombinante para estudo da função foi a proteína MEG4.1. Incubação da mesma com eritrócitos in vitro levou a agregação dos mesmos (Martins et al., 2014). Microscopia confocal utilizando um anticorpo anti-MEG4.1 em vermes adultos demonstrou que na glândula esofágica é possível detectar esta proteína circundando leucócitos, que se encontram agrupados (Li et al., 2013*). Desta maneira é possível supor que o mesmo tipo de fenômeno que levou a agregação de eritrócitos in vitro possa ser responsável pelas observações in vivo com leucócitos.

* Artigo do candidato no tema. 


\section{5- Evolução da sequência codificante de MEGs e outros genes codificando proteínas expostas pelo parasito no hospedeiro definitivo.}

Vários genes de patógenos envolvidos em evasão do sistema imune humano possuem dN/dS (razão das taxas de mutação não-sinônimas e sinônimas) maiores que 1, indicando um contexto de seleção positiva (Yang and Bielawski, 2000). De fato, este altos índices foram atribuídos a uma rápida co-evolução entre hospedeiros e patógenos que foi considerada análoga a uma corrida armamentista (Aguileta et al., 2009) e, portanto, seria de grande interesse verificar se genes codificantes de proteínas localizadas na interface parasito-hospedeiro na esquistossomose, incluindo MEGs, estariam sujeitos a tais tipos de pressão.

Análises das taxas de mutação nas regiões codificantes de MEGs foram realizadas através da comparação das taxas de mutação não-sinônimas e sinônimas, inferidas a partir da comparação da sequência do transcrito de $S$. mansoni com ortólogos de $S$. haematobium e S. japonicum. Foi verificado que MEGs possuíam um valor de $\mathrm{dN} / \mathrm{dS}$ significativamente maior do que a média de todos os genes de S. mansoni nas comparações com as duas espécies. Além disso, mesmo quando considerados apenas genes codificando proteínas com peptídeo sinal ou aquelas que foram detectadas na superfície do tegumento, os valores de $\mathrm{dN} / \mathrm{dS}$ ainda eram significativamente menores que os observados para as MEGs (Phillipsen et al., 2015*).

Além disso, verificou-se que os valores de dN/dS para a região da proteína madura de MEGs era significativamente maior que aquele observado para a região codificando o peptídeo sinal. Devido ao fato dos peptídeos sinais estarem ausentes na proteína madura e, portanto, não estarem expostos na superfície do parasita, levantou-se a hipótese de que o fator que poderia estar levando a este alto nível de mutações não-sinônimas em MEGs seria a exposição ao sistema imune. Os valores de dN/dS observados para porções da proteína madura de MEGs em alguns casos ultrapassa o valor de 1 , o que indicaria um processo de seleção positiva (Phillipsen et al., 2015*).

Análises de valores de dN/dS para uma outra família de genes codificando as proteínas Venon Alergen-Like (VAL) foi realizada. Esta família de proteínas é divididas em dois grupos (Chalmers et * Artigo do candidato no tema. 
al., 2008), sendo que o grupo 1 representam proteínas secretadas, com a presença de um peptídeo sinal em sua sequência, e o grupo 2 proteínas intracelulares. Proteínas desta família já foram descritas em secreções de Ancylostoma caninum (Hawdon et al., 1999) e em secreções de cercarias mecanicamente transformadas de S. mansoni (Curwen et al., 2006). Foi possível notar que os valores de dN/dS para genes VAL do grupo 1 através da comparação de ortologos de S. mansoni com S. haematobium eram significativamente maiores que as médias da valores de $\mathrm{dN} / \mathrm{dS}$ envolvendo todos os genes, genes codificando proteínas secretadas ou genes expostos no tegumento . Além disso, foi possível notar que genes do grupo 1 apresentam valores de dN/dS significativamente maiores que proteínas do grupo 2 e do que VALs contendo peptídeo sinal em comparações entre genes de C. elegans e C. briggsae. Foi verificado também através da comparação entre parálogos de $S$. mansoni que aqueles genes expressos no hospedeiro humano possuíam valores de dN/dS significativamente maiores quando comparados entre si, do que o mesmo tipo de comparação realizada com VALs expressas no hospedeiro intermediário (Phillipsen et al., 2015*).

Grande parte dos genes codificando proteínas previamente detectadas na superfície do tegumento do parasita apresentaram valor baixo de dN/dS. Este fato fornece suporte adicional a teoria de que grande parte das proteínas da superfície do tegumento estão inacessíveis ao sistema imune do hospedeiro devido a presença do membranocalix. Interessantemente, dois candidatos vacinais expostos na superfície do parasita, Sm29 e TSP-2, apresentavam altos valores de dN/dS. No caso de TSP-2, este alto valor restringia-se ao domínio hidrofílico da proteína voltado para o exterior da membrana, o que evidencia uma possível influencia da pressão evolutiva do sistema imune (Phillipsen et al., 2015*).

\section{Considerações finais (capítulo 1).}

O estudo das interações entre parasito-hospedeiro na esquistossomose é um tema complexo, onde ainda existem grandes lacunas no entendimento dos mecanismos de escape do sistema imune pelo parasito. A descrição de um sistema genético intrincado com o objetivo de produção de proteínas secretadas variantes, representada pelas MEGs traz uma importante contribuição. Note-se que a variação gerada pelo splicing alternativo das MEGs deve se somar ao provável alto nível de polimorfismo derivado da rápida evolução deste grupo de genes, gerando um perfil bastante variado de antígenos. Desta maneira propusemos que o sistema genético presente em MEGs teria como objetivo

* Artigo do candidato no tema. 
gerar variação antigênica que teria como principal objetivo inibir uma resposta imune efetiva contra estes antígenos.

A concentração da expressão dos produtos destes genes em interfaces de interação com o hospedeiro definitivo, como o tegumento e o esôfago do parasita, e em secreções indica a efetiva interação dos mesmo com células e proteínas humanas. De fato, já foi demonstrado que MEG-4 interage com leucócitos ingeridos pelo parasita ( $\mathrm{Li}$ et al., 2013*) e dados preliminares obtidos pelo nosso grupo de pesquisa apontam para outras interações com proteínas e células humanas. Desta maneira pode-se considerar que o estudo das MEGs representa um novo e promissor campo para entendimento dos mecanismos envolvidos na interação do S. mansoni com o hospedeiro definitivo.

\section{Contribuições do candidato ao tema (Capitulo 1).}

Almeida GT, Amaral MS, Beckedorff FC, Kitajima JP, DeMarco R, Verjovski-Almeida S. Exploring the Schistosoma mansoni adult male transcriptome using RNA-seq. Exp Parasitol. 2012 Sep;132(1):22-31.

Berriman M, Haas BJ, LoVerde PT, Wilson RA, Dillon GP, Cerqueira GC, Mashiyama ST, AlLazikani B, Andrade LF, Ashton PD, Aslett MA, Bartholomeu DC, Blandin G, Caffrey CR, Coghlan A, Coulson R, Day TA, Delcher A, DeMarco R, Djikeng A, Eyre T, Gamble JA, Ghedin E, Gu Y, HertzFowler C, Hirai H, Hirai Y, Houston R, Ivens A, Johnston DA, Lacerda D, Macedo CD, McVeigh P, Ning Z, Oliveira G, Overington JP, Parkhill J, Pertea M, Pierce RJ, Protasio AV, Quail MA, Rajandream MA, Rogers J, Sajid M, Salzberg SL, Stanke M, Tivey AR, White O, Williams DL, Wortman J, Wu W, Zamanian M, Zerlotini A, Fraser-Liggett CM, Barrell BG, El-Sayed NM. The genome of the blood fluke Schistosoma mansoni. Nature. V. 460(7253), p352-8, 2009.

DeMarco R, Mathieson W, Dillon GP, Wilson RA. Schistosome albumin is of host, not parasite, origin. Int J Parasitol. 2007 Sep;37(11):1201-8.

DeMarco R, Mathieson W, Manuel SJ, Dillon GP, Curwen RS, Ashton PD, Ivens AC, Berriman M, Verjovski-Almeida S, Wilson RA. Protein variation in blood-dwelling schistosome worms generated by differential splicing of micro-exon gene transcripts. Genome Res. 20(8):1112-21, 2010. 
Li XH, de Castro-Borges W, Parker-Manuel S, Vance GM, DeMarco R, Neves LX, Evans GJ, Wilson RA.The schistosome oesophageal gland: initiator of blood processing. PLoS Negl Trop Dis. 2013 Jul 25;7(7):e2337.

Lopes JL, Orcia D, Araujo AP, DeMarco R, Wallace BA. Folding factors and partners for the intrinsically disordered protein micro-exon gene 14 (MEG-14). Biophys J. 2013 Jun 4;104(11):251220.

Philippsen GS, Wilson RA, DeMarco R. Accelerated evolution of schistosome genes coding for proteins located at the host-parasite interface. Genome Biol Evol. 2015 Jan 6;7(2):431-43.

\section{Referencias. (Capitulo 1)}

Aguileta G, Refrégier G, Yockteng R, Fournier E, Giraud T. Rapidly evolving genes in pathogens: methods for detecting positive selection and examples among fungi, bacteria, viruses and protists. Infect Genet Evol. 2009 Jul;9(4):656-70.

Braschi S, Wilson RA. Proteins exposed at the adult schistosome surface revealed by biotinylation.Mol Cell Proteomics. 2006 Feb;5(2):347-56.

Caffrey CR, McKerrow JH, Salter JP, Sajid M. Blood 'n' guts: an update on schistosome digestive peptidases. Trends Parasitol. 2004 May;20(5):241-8.

Cardoso FC, Macedo GC, Gava E, Kitten GT, Mati VL, de Melo AL, Caliari MV, Almeida GT, Venancio TM, Verjovski-Almeida S, Oliveira SC. Schistosoma mansoni tegument protein Sm29 is able to induce a Th1-type of immune response and protection against parasite infection. PLoS Negl Trop Dis. 2008 Oct 1;2(10):e308.

Colley DG, Secor WE. Immunology of human schistosomiasis. Parasite Immunol. 2014 Aug;36(8):347-57.

Curwen RS, Ashton PD, Sundaralingam S, Wilson RA. Identification of novel proteases and immunomodulators in the secretions of schistosome cercariae that facilitate host entry. Mol Cell Proteomics. 2006;5(5):835-44.

Figueiredo BC, Ricci ND, de Assis NR, de Morais SB, Fonseca CT, Oliveira SC. Kicking in the Guts: Schistosoma mansoni Digestive Tract Proteins are Potential Candidates for Vaccine Development. Front Immunol. 2015 Jan 28;6:22. 
Hall SL, Braschi S, Truscott M, Mathieson W, Cesari IM, Wilson RA. Insights into blood feeding by schistosomes from a proteomic analysis of worm vomitus. Mol Biochem Parasitol. 2011 Sep;179(1):18-29.

Hawdon JM, Narasimhan S, Hotez PJ. Ancylostoma secreted protein 2: cloning and characterization of a second member of a family of nematode secreted proteins from Ancylostoma caninum. Mol Biochem Parasitol. 1999; 99(2):149-65.

Iwamura Y, Yonekawa H, Irie Y. Detection of host DNA sequences including the H-2 locus of the major histocompatibility complex in schistosomes. Parasitology. 1995 Feb;110 ( Pt 2):163-70.

Jenkins SJ, Hewitson JP, Jenkins GR, Mountford AP. Modulation of the host's immune response by schistosome larvae. Parasite Immunol. 2005; 27(10-11):385-93.

Lawrence, J. D. (1973) Ingestion of Red Blood-Cells by Schistosoma-Mansoni. J Parasitol 59, 60-63

Loukas A, Jones MK, King LT, Brindley PJ, McManus DP. Receptor for Fc on the surfaces of schistosomes. Infect Immun. 2001 Jun;69(6):3646-51.

Wilson RA. Proteomics at the schistosome-mammalian host interface: any prospects for diagnostics or vaccines? Parasitology. 2012 Aug;139(9):1178-94.

Martins VP, Morais SB, Pinheiro CS, Assis NR, Figueiredo BC, Ricci ND, Alves-Silva J, Caliari MV, Oliveira SC. Sm10.3, a member of the micro-exon gene 4 (MEG-4) family, induces erythrocyte agglutination in vitro and partially protects vaccinated mice against Schistosoma mansoni infection. PLoS Negl Trop Dis. 2014 Mar 20;8(3):e2750.

Tran MH, Pearson MS, Bethony JM, Smyth DJ, Jones MK, Duke M, Don TA, McManus DP, Correa-Oliveira R, Loukas A. Tetraspanins on the surface of Schistosoma mansoni are protective antigens against schistosomiasis. Nat Med. 2006 Jul;12(7):835-40.

Salzet M, Capron A, Stefano GB. Molecular crosstalk in host-parasite relationships: schistosome- and leech-host interactions. Parasitol Today. 2000 Dec;16(12):536-40.

Uversky VN. Intrinsically disordered proteins from A to Z. Int J Biochem Cell Biol. 2011 Aug;43(8):1090-103.

Williams DL, Sayed AA, Ray D, McArthur AG. Schistosoma mansoni albumin, a major defense against oxidative damage, was acquired by lateral gene transfer from a mammalian host. Mol Biochem Parasitol. 2006 Dec;150(2):359-63.

Zhang W, Li J, Duke M, Jones MK, Kuang L, Zhang J, Blair D, Li Y, McManus DP. 
Inconsistent protective efficacy and marked polymorphism limits the value of Schistosoma japonicum tetraspanin-2 as a vaccine target. PLoS Negl Trop Dis. 2011;5(5):e1166. 


\section{Capítulo 2- Estudo da dinâmica e papel septinas em Schistosoma mansoni.}

\section{1- O estudo de proteínas de citoesqueleto em Schistosoma.}

Os três principais tipos de filamentos proteicos que compõem o citoesqueleto são filamentos de actina, microtúbulos e filamentos intermediários. Considerando o papel importante do citoesqueleto em uma serie de funções celulares, o detalhamento dos papeis destas proteínas em esquistossomas é de grande importância para o entendimento da organização celular neste ramo evolutivo. Por exemplo, já foi demonstrado que proteínas de citoesqueleto possuem uma distribuição diferencial na estrutura do tegumento do parasita (Matsumoto et al., 1988; Jones et al., 2004), o que sugere que uma serie de estruturas especializadas deste tecido são derivadas de diferentes tipos de filamentos. De fato, preparações de tegumento analisadas através de proteômica apresentaram um enriquecimento em proteínas de citoesqueleto em relação aos vermes desnudos (Van Balkon et al., 2005).

Análise de bancos de transcritos de S. mansoni demonstrou que o mesmo possui os principais componentes do sistema citoesquelético baseado em actina e tubulina (Jones et al., 2004). Estudos utilizando o composto faloidina com um marcador fluorescente permitiram mapear a distribuição de filamentos de f-actina em diversas fases do ciclo de vida do parasita, estando fortemente associados com células musculares e células flama (Mair et al., 2000; Mair et al., 2003; Bahia et al., 2006). Além disso, há dados sobre a presença de filamentos circulares de actina associadas a estruturas sensoriais na superfície do parasita adulto (Zhou e Podesta, 1992) e também de espinhos que se encontram na superfície do parasita e que consistem em filamentos de actina hexagonalmente empacotados (Cohen et al., 1992).

Estudos de microscopia confocal demonstraram a presença de fibras de tubulina em uma serie de tecidos, em vários estágios do ciclo de vida do parasita. Fibras contendo alfa-tubulina ou betatubulina são detectáveis em estruturas ciliares presentes em papilas sensoriais em cercarias, no sistema protonefrídico de cercarias e adultos e em placas epidérmicas de miracídios. Além disso, elas estão presentes em projeções neurais e na periferia das glândulas acetabulares em cercarias (Collins et al., 2011). 
Em contraste, evidências para a presença de filamentos intermediários em schistosomas ainda é bastante escassa, com poucos transcritos disponíveis em bancos públicos, havendo apenas estudos de imunocalização utilizando anticorpos heterólogos que sugeriram a presença dos mesmos em células subtegumentais e musculares (Jones et al., 2004 ; Sato e Kamiya, 2000).

\section{2- Septinas}

As septinas foram inicialmente descritas como proteínas de Saccharomyces cerevisiae que eram essenciais para o processo de citocinese na divisão celular, sendo essenciais para a formação de brotos neste organismo (Hartwell, 1971; Byers e Goetsch, 1976). Posteriormente, verificou-se que filamentos de septina estavam envolvidas em uma serie de processos celulares tais como formação do fuso mitótico (Spiliotis et al., 2005), formação de barreiras de difusão em membranas (Dobbelaere e Barral, 2004), controle do ciclo celular (Kremer et al., 2007), transporte vesicular (Hsu et al., 1998) entre outros. Devido a formação dos filamentos a partir desta proteína e da sua associação com membranas celulares, filamentos de actina e microtúbulos, vem sendo sugerido que filamentos de septinas sejam considerados o quarto componente do citoesqueleto (Mostowy e Cossart, 2012). Septinas foram primeiramente descritas como restritas a eucariotos opisthokonta (clado que inclui animais e fungos), mas estudos mais recentes demonstraram a sua presença também em outras linhagens eucarióticas como algas verdes, algas pardas e ciliados (Nishiyama et al., 2011). O número de diferentes cópias de septinas em um organismo é bastante variável, sendo que algumas algas verde possuem apenas uma cópia, enquanto que humanos apresentam treze cópias distintas (Beise e Trimble, 2011)

Septinas possuem um domínio do tipo P-loop GTPase que é definido pela presença dos motivos Walker A (GxxGxGKST), Walker B (DxxG) e de especificidade para GTP- (xKxD) (Hall e Russel, 2004). Em algumas septinas o domínio GTPase encontra-se ativo, sendo capaz de hidrolisar nucleotídeos, enquanto que em outros casos não há atividade hidrolítica, sendo a septina capaz apenas de ligar nucleotídeos. O domínio GTPase é flanqueado por regiões amino e carboxi terminais de comprimentos variáveis. Grande parte das septinas possuem uma região básica na porção aminoterminal adjacente ao domínio GTPase, que possui a propriedade de ligação a fosfoinositídeos, sendo um importante componente para interação de septinas com membranas (Casamayor e Snider, 2003; Berin et al., 2010). Regiões carboxi-terminais tendem a formar estruturas do tipo coiled-coil que são 
importantes para o estabelecimento de interações proteína-proteína (Casamayor e Snider, 2003).

Septinas de mamíferos foram divididas em quatro subgrupos distintos denominados SEPT2, SEPT3, SEPT6 e SEPT7, baseado nos nomes de seus membros fundadores. Cada um destes grupos estão representados em mamíferos, mas somente dois ou três grupos estão representados em organismos modelos de outros ramos evolutivos como Drosophila melanogaster e Caenorhabditis elegans. Análises de diversos complexos de mamíferos indicou que septinas dos diferentes grupos estão distribuídas de forma não-randômica, com septinas de diferentes grupos ocupando posições especificas num heteropolímero (Sellin et al., 2011).

Septinas organizam-se em complexos hetero-oligoméricos que irão se polimerizar para a formação de filamentos. Filamentos de septinas não são polares, sendo semelhantes neste aspecto a filamentos intermediários (Mostowy e Cossart, 2012). Em mamíferos, tais oligômeros existem como subunidades de seis ou oito elementos. Normalmente, hexâmeros são compostos de combinações de membros dos subgrupos SEPT2, SEPT6 e SEPT7 e octâmeros adicionariam membros do subgrupo SEPT3 (Sellin et al., 2011). A estrutura cristalográfica de um hexâmero de septinas humanas (Figura 4) foi resolvida a baixa resolução e mostra uma organização linear para o filamento, onde uma das interfaces de interação é constituída pelos domínios GTPase de diferentes monômeros que interagem entre si e, uma segunda interface, é composta de domínios $\mathrm{N}$ e C terminais que também interagem entre si (Sirajuddin et al., 2007).

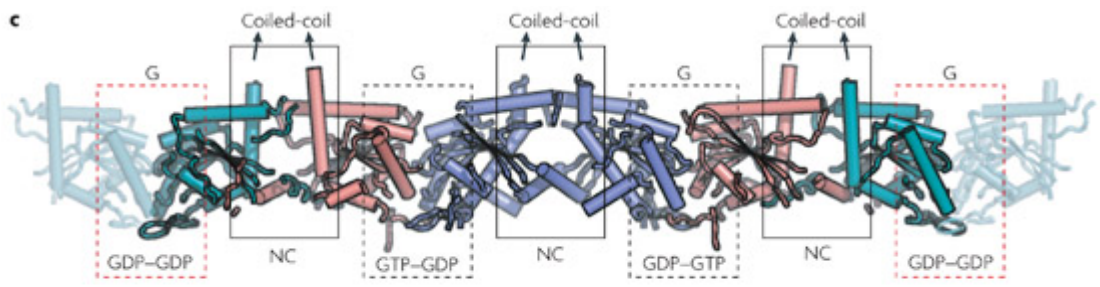

Figura 4- representação da estrutura do hexâmero de septinas de mamíferos formando um filamento alternando interfaces do domínio GTPase $(\mathrm{G})$ e dos domínios N e C terminais (NC). Retirado de Weirich et al., 2008. 


\section{3-Septinas em Schistosoma mansoni}

Uma busca direcionada no genoma de $S$. mansoni permitiu a identificação de 4 diferentes genes codificando ortólogos de septinas humanas. Estes foram denominados SmSEPT5, SmSEPT7.1, SmSEPT7.2 e SmSEPT10, baseado na similaridade com septinas humanas. Análises filogenéticas destas septinas revelaram que estas pertencem aos grupos SEPT2, SEPT6 e SEPT7 (Figura 5), estando ausente membros representantes do grupo SEPT3, em vários platelmintos analisados. Além disso, existe apenas um membro de cada grupo, exceto no caso do grupo SEPT7 que possui dois membros. Este cenário é bastante contrastante com aquele observado em humanos onde há 13 diferentes septinas descritas (Figura 5), sendo que 3 dos 4 grupos possuem múltiplos membros (Zeraik et al., 2013*). Adicionalmente, o grupo SEPT7 possui apenas um representante em humanos.

A presença das três famílias de septinas pertencentes ao grupos responsáveis pela formação de hexâmeros em vertebrados sugere que as septinas de S. mansoni devam se organizar de forma semelhante. Interessantemente, a análise da expressão das diversas septinas de $S$. mansoni ao longo do ciclo de vida do parasita com a utilização da técnica de Real-Time PCR demonstra um perfil semelhante em todas elas, compatível com o que seria esperado na formação de um heterocomplexo funcional contendo várias septinas (Zeraik et al., 2013*). Além disso, a co-expressão das proteínas SmSEPT5, SmSEPT7.2 e SmSEPT10 em sistema recombinante resultou na formação de um heterocomplexo funcional, capaz da formação de filamentos in vitro (Zeraik et al., 2014a*).

A imunolocalização das proteínas SmSEPT5 e SmSEPT10 em diversos ciclos de vida apresentaram padrões bastante semelhantes, fornecendo evidências adicionais de que provavelmente 0 complexo nativo envolve a formação de heteroligômeros. Observou-se que em vermes adultos e miracídios as septinas se co-localizavam com filamentos de actina em células musculares. Além disso, foi possível notar enriquecimentos de septinas em estruturas especializadas, como placas epidérmicas em miracídios, células germinativas em esporocistos e dutos de protenefrídios presentes em cercarias (Zeraik et al., 2013*).

* Artigo do candidato no tema. 


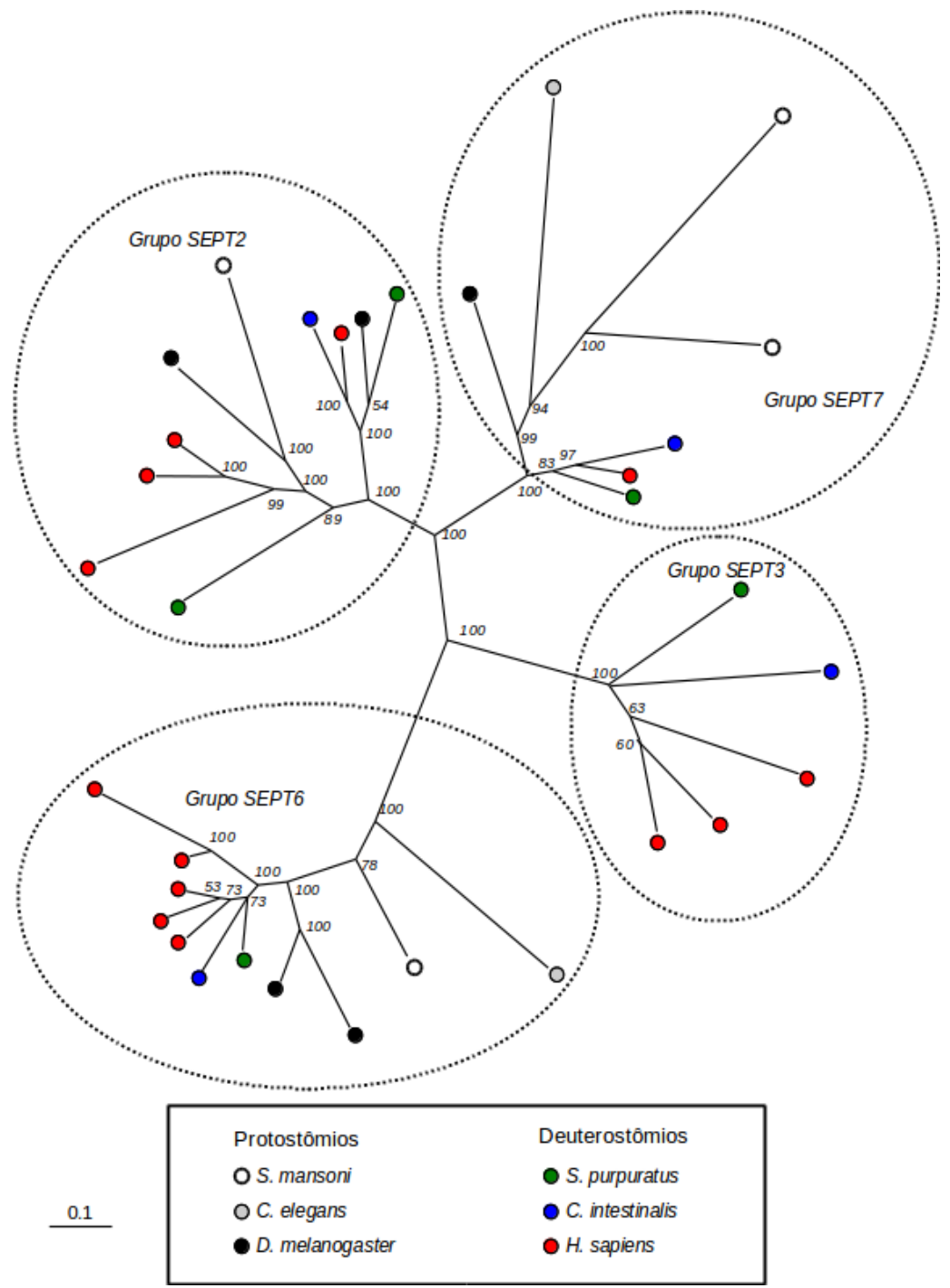

Figura 5- Árvore filogenética gerada a partir de inferência bayesiana de um alinhamento múltiplo de domínios GTPases de septinas de diversos organismos. Números nos nós da árvore indicam as probabilidades posteriores calculadas pelo programa Mr. Bayes. Círculos pontilhados indicam os quatro grupos de septinas (Adaptado de Zeraik et al., 2013).

Assim, como previamente observado em septinas de vertebrados, a exposição de septinas de $S$. mansoni ao composto forchlorfenuron (FCF) levou a uma mudança na dinâmica de formação de filamentos. Surpreendentemente, a exposição de parasitas vivos ao FCF levou a um estado de paralisia, que era revertida quando da retirada do composto. Devido ao enriquecimento de septinas em fibras musculares em diversos estágios é possível que uma ação direta do FCF em fibras de septinas neste tecido resulte em perda da função muscular (Zeraik et al., 2014a*).

* Artigo do candidato no tema. 
A proteína SmSEPT10 expressa em sistema recombinante foi cristalizada e suas estruturas tridimensionais com resolução de aproximadamente $2 \AA$, tanto para forma complexada com GTP quanto com GDP. Esta foi a primeira estrutura de uma septina com alta resolução já obtida e permitiu, pela primeira vez, a descrição detalhada de uma mudança conformacional da proteína através do escorregamento de uma folha-beta quando da troca de GTP por GDP. A partir desses resultados, foi proposto que tal mudança conformacional provavelmente estaria envolvida na dinâmica de interação de septinas com membranas biológicas (Zeraik et al., 2014b).

\section{Considerações finais (Capítulo 2)}

A descrição de septinas em Schistosoma adicionam uma nova proteína de citoesqueleto ao repertório utilizado pelo parasita para formação de diversas estruturas celulares. Evidências coletadas sugerem que as mesmas devem se organizar em filamentos de maneira semelhante a aquela descrita para septinas de mamíferos. O menor número de membros em cada família, quando comparado com humanos, sugere que platelmintos não sofreram o processo de diversificação verificado em mamíferos. Apesar disso, foi possível verificar a formação de um filamento composto de um membro dos subgrupos SEPT2, SEPT6 e SEPT7, de forma análoga ao filamento humano cuja a estrutura já foi caracterizada, sugerindo que o filamento de Schistosoma deve ter uma estrutura semelhante e representaria um sistema análogo a aquele presentes em ancestrais de mamíferos, anteriormente a diversificação dos membros das famílias.

O fato de que septinas são localizadas em diversas fases do ciclo de vida do parasita e, em muitos casos, enriquecidas em certos tecidos especializados reforça a ideia da sua importância na formação de estruturas essenciais para as funções do parasito. O tratamento com FCF levando a paralisia reversível do parasita sugere que pelo menos parte destas funções deva estar relacionada a estruturas de células musculares ligadas à contração. O estudo mais detalhado deste grupo de proteínas permitirá entender melhor se o papel de septina em schistosomas é semelhante a aquele descrito em outros organismos.

* Artigo do candidato no tema. 


\section{Contribuições do candidato ao tema (Capitulo 2).}

Zeraik AE, Rinaldi G, Mann VH, Popratiloff A, Araujo AP, DeMarco R\#, Brindley PJ\#. Septins of Platyhelminths: identification, phylogeny, expression and localization among developmental stages of Schistosoma mansoni. PLoS Negl Trop Dis. 2013; 7(12):e2602.

Zeraik AE, Galkin VE, Rinaldi G, Garratt RC, Smout MJ, Loukas A, Mann VH, Araujo AP, DeMarco R\#, Brindley $\mathrm{PJ}^{\#}$. Reversible paralysis of Schistosoma mansoni by forchlorfenuron, a phenylurea cytokinin that affects septins. Int J Parasitol. 2014a; 44(8):523-31.

Zeraik AE, Pereira HM, Santos YV, Brandão-Neto J, Spoerner M, Santos MS, Colnago LA, Garratt RC, Araújo AP, DeMarco R. Crystal structure of a Schistosoma mansoni septin reveals the phenomenon of strand slippage in septins dependent on the nature of the bound nucleotide. J Biol Chem. 2014b;289(11):7799-811.

${ }^{\#}$ Co-autores correspondentes.

\section{Referencias (Capitulo 2).}

Bahia D, Avelar LG, Vigorosi F, Cioli D, Oliveira GC, Mortara RA. The distribution of motor proteins in the muscles and flame cells of the Schistosoma mansoni miracidium and primary sporocyst. Parasitology. 2006 Sep;133(Pt 3):321-9.

Beise N, Trimble W. Septins at a glance. J Cell Sci. 2011 Dec 15;124(Pt 24):4141-6.

Bertin A, McMurray MA, Thai L, Garcia G 3rd, Votin V, Grob P, Allyn T, Thorner J, Nogales E. Phosphatidylinositol-4,5-bisphosphate promotes budding yeast septin filament assembly and organization. J Mol Biol. 2010 Dec 10;404(4):711-31.

Byers B, Goetsch L. A highly ordered ring of membrane-associated filaments in budding yeast. J Cell Biol. 1976 Jun;69(3):717-21.

Casamayor A, Snyder M. Molecular dissection of a yeast septin: distinct domains are required 
for septin interaction, localization, and function. Mol Cell Biol. 2003 Apr;23(8):2762-77.

Cohen C, Reinhardt B, Castellani L, Norton P, Stirewalt M. Schistosome surface spines are "crystals" of actin. J Cell Biol. 1982 Dec;95(3):987-8.

Collins JJ 3rd, King RS, Cogswell A, Williams DL, Newmark PA. An atlas for Schistosoma mansoni organs and life-cycle stages using cell type-specific markers and confocal microscopy. PLoS Negl Trop Dis. 2011;5(3):e1009.

Dobbelaere J, Barral Y. Spatial coordination of cytokinetic events by compartmentalization of the cell cortex. Science. 2004 Jul 16;305(5682):393-6.

Hall PA, Russell SE. The pathobiology of the septin gene family. J Pathol. 2004; 204(4):489505.

Hartwell LH. Genetic control of the cell division cycle in yeast. IV. Genes controlling bud emergence and cytokinesis. Exp Cell Res. 1971 Dec;69(2):265-76.

Hsu SC, Hazuka CD, Roth R, Foletti DL, Heuser J, Scheller RH. Subunit composition, protein interactions, and structures of the mammalian brain sec6/8 complex and septin filaments. Neuron. 1998 Jun;20(6):1111-22.

Jones MK, Gobert GN, Zhang L, Sunderland P, McManus DP. The cytoskeleton and motor proteins of human schistosomes and their roles in surface maintenance and host-parasite interactions. Bioessays. 2004; 26(7):752-65.

Kremer BE, Adang LA, Macara IG. Septins regulate actin organization and cell-cycle arrest through nuclear accumulation of NCK mediated by SOCS7. Cell. 2007;130(5):837-50.

Mair GR, Maule AG, Day TA, Halton DW. A confocal microscopical study of the musculature of adult Schistosoma mansoni. Parasitology. 2000;121 ( Pt 2):163-70.

Mair GR, Maule AG, Fried B, Day TA, Halton DW. Organization of the musculature of schistosome cercariae. J Parasitol. 2003 Jun;89(3):623-5.

Matsumoto Y, Perry G, Levine RJ, Blanton R, Mahmoud AA, Aikawa M. Paramyosin and actin in schistosomal teguments. Nature. 1988 May 5;333(6168):76-8.

Mostowy S, Cossart P. Septins: the fourth component of the cytoskeleton. Nat Rev Mol Cell Biol. 2012 Feb 8;13(3):183-94.

Nishihama R, Onishi M, Pringle JR. New insights into the phylogenetic distribution and evolutionary origins of the septins. Biol Chem. 2011 Aug;392(8-9):681-7.

Sato H, Kamiya H.Immunofluorescent localization of intermediate filaments (IFs) in 
helminths using anti-mammalian IFs monoclonal antibody. J Parasitol. 2000 Aug;86(4):711-5.

Sellin ME, Sandblad L, Stenmark S, Gullberg M. Deciphering the rules governing assembly order of mammalian septin complexes. Mol Biol Cell. 2011 Sep;22(17):3152-64.

Sirajuddin M, Farkasovsky M, Hauer F, Kühlmann D, Macara IG, Weyand M, Stark H, Wittinghofer A. Structural insight into filament formation by mammalian septins. Nature. 2007; 449(7160):311-5.

Spiliotis ET, Kinoshita M, Nelson WJ. A mitotic septin scaffold required for Mammalian chromosome congression and segregation. Science. 2005 Mar 18;307(5716):1781-5.

van Balkom BW, van Gestel RA, Brouwers JF, Krijgsveld J, Tielens AG, Heck AJ, van Hellemond JJ. Mass spectrometric analysis of the Schistosoma mansoni tegumental sub-proteome. J Proteome Res. 2005 May-Jun;4(3):958-66.

Weirich CS, Erzberger JP, Barral Y. The septin family of GTPases: architecture and dynamics. Nat Rev Mol Cell Biol. 2008; 9(6):478-89.

Zhou Y, Podesta RB. Ring-shaped organization of cytoskeletal F-actin associated with surface sensory receptors of Schistosoma mansoni: a confocal and electron microscopic study. Tissue Cell. 1992;24(1):37-49. 


\section{Capítulo 3- estudo da estrutura genômica de S. mansoni e sua evolução.}

\section{1- A estrutura do genoma de Schistosoma mansoni.}

O Schistosoma mansoni é um organismo diploide que possui um genoma de aproximadamente 363 megabases (Mbp), codificando aproximadamente 11.000 genes (Berriman et al., 2009; Protasio et al., 2012). O genoma está organizado em sete pares de cromossomos autossômicos, mais um par de cromossomos sexuais do tipo ZW, que possuem tamanhos entre 65 e 9 Mbp (Protasio et al., 2012). Cromossomos de S. mansoni possuem em sua extremidade telômeros com motivos de repetição TTAGGG, cuja sequência é idêntica a aquela encontrada em humanos (Hirai e Loverde, 1996).

Cerca de $40 \%$ do genoma é repetitivo, sendo que destes $~ 15 \%$ podem ser atribuídos a retrotransposons do tipo não-LTR, $\sim 5 \%$ a transposons do tipo LTR, $\sim 1.5 \%$ a retrotransposons Penelope-Like e $\sim 0.5 \%$ a transposons de DNA ( Berriman et al., 2009*; Venancio et al.,2010*; Jacinto et al., 2011*). Já foi relatado que a região específica do cromossomo sexual feminino (W) possui abundância de elementos repetitivos específicos, estando organizados em blocos, e que a presença dos mesmos pode estar relacionada ao fenômeno de heterocromatização de parte do cromossomo W durante o desenvolvimento do mesmo em vermes adultos (Lepesant et al., 2012).

\section{2-Elementos de transposição e sua dinâmica em S. mansoni.}

Elementos de transposição são componentes genéticos móveis que são encontrados em grande número na maioria dos genomas eucarióticos, sendo considerados um fonte importante de variação genética. Eles podem ser classificados em retrotransposons (Classe I) e transposons de DNA (Classe II), que possuem mecanismos de replicação bastante distintos. Retrotransposons tem sua transposição baseada na integração de material genético formado a partir da transcrição reversa do mRNA produzido a partir de um elemento transcricionalmente ativo. Devido ao fato da cópia original ficar preservada, este tipo de mecanismo é muitas vezes referido como de "copiar e colar". Em contraste, transposons de DNA transpõem através da excisão do elemento e sua reinserção em nova localização do genoma com a utilização de uma transposase. Devido a estas características, este segundo tipo de mecanismo é

* Artigo do candidato no tema. 
muitas vezes referido como de “cortar e colar” (Wicker et al., 2007; Levin e Moran, 2011).

Elementos transponíveis podem ser descritos como elementos genéticos parasitários devido ao fato de poderem se replicar autonomamente e se espalhar em uma população, mesmo quando os eventos necessários para sua perpetuação gerem mutações deletérias para o organismo hospedeiro (Hurst e Werren, 2001). No entanto, já foram descritos diversos casos onde elementos de transposição foram “domesticados” passando a exercer funções úteis para o metabolismo celular (Sinzelle et al., 2009), bem como casos onde fragmentos de elementos de transposição são fixados de forma a atuarem como elementos genéticos de genes do genoma hospedeiro, como promotores alternativos, sítios de ligação de fatores de transcrição, sinais de poliadenilação, entre outros (Feschotte, 2008; Oliver e Greene, 2009). Além disso, diversas evidências vem se acumulando, demonstrando a importância deste tipo de elemento para a evolução de genomas de organismos eucariotos, nos quais estes elementos atuariam como uma fonte de variação genética ao estimularem eventos de recombinação e mutação (Oliver e Greene, 2009; Nakayashi, 2011).

Dezenas de retrotransposons já foram descritos no genoma do S. mansoni (Drew e Brindley, 1997; Drew et al.,1998; Copeland et al., 2003; DeMarco et al., 2004; Laha et al., 2004; Copeland et al., 2005; DeMarco et al., 2005; Laha et al., 2005) demonstrando a prevalência de tais elementos no genoma do parasita. Os transposons do tipo não-LTR de S. mansoni estão distribuídos nos clados CR1, R2 e RTE , enquanto que transposons do tipo LTR são representados nos clados Ty3 e Pao (Venancio et al., 2010*). A representação de tais elementos no genoma é bastante distinta, havendo elementos que respondem a quase 4\% do genoma, enquanto outros possuem representação bastante reduzida.

Através da análise de bibliotecas de EST foi possível verificar que retrotransposons constituíam uma fração considerável do transcriptoma de S. mansoni, sendo que em cercaria $14 \%$ do total de ESTs apresentavam identidade com sequências de transposons, enquanto que em outros estágios esta fração era de 3 a 7,5 \% do total de ESTs (DeMarco et al., 2004*). Em adição, a análise destas sequências de ESTs permitiu a reconstrução de 22 diferentes retrotransposons, sendo que quatorze destes apresentavam ORFs completas, com características preservadas para um elemento autônomo (DeMarco et al., 2004*; DeMarco et al., 2005*). De fato, foi demonstrado para quatro destes elementos que era possível, via reações de RT-PCR, obter produtos com tamanhos correspondentes ao esperado para

* Artigo do candidato no tema. 
transcritos de cópias completas (DeMarco et al., 2004*).

Verificou-se que duas famílias de retrotransposons, SR2 e Perere-3/SR3, possuíam uma alta representação no genoma do S. mansoni totalizando aproximadamente 7,8 \% do genoma do S. mansoni, enquanto que em $S$. japonicum estas duas famílias representam apenas 3,5 \% do genoma. A análise filogenética das diversas cópias destes elementos indica uma pequena distância entre as cópias dos elementos SR2 e do ramo Perere-3 da família Perere-3/SR3, sendo assim consistente com o que seria esperado de uma expansão recente no número de cópias destes elementos. Devido a expansão recente destas duas famílias e ao fato do genoma do S. mansoni (espécie africana) ser mais rico em elementos de transposição que o de $S$. japonicum (espécie asiática), especulou-se que estas diferenças poderiam ser reflexo da adaptação do parasita a um novo ambiente quando da migração ancestral da Ásia para a África (Venancio et al., 2010*). Além disso, experimentos de PCR quantitativo utilizando DNA genômico de isolados americanos e africanos detectaram um maior número de cópias de quatro retrotranposons e dois transposons de DNA, sugerindo uma recente expansão no número de cópias destas famílias (Wijayawardena et al., 2015)

Uma atuação muito mais discreta é observada para transposons de DNA que possuem uma baixa representação no genoma de S. mansoni. Foram descritos transposons de DNA das superfamílias Merlin, CACTA e Mutator (Feschotte, 2004; DeMarco et al., 2006*; Jacinto et al., 2010*). O transposon da superfamília CACTA descrita em S. mansoni representou o primeiro exemplo de um elemento de tal superfamília em metazoários (DeMarco et al., 2006*).

Em adição, várias sequências repetitivas que possuíam um promotor para polimerase III, um 3' rico em AT produzindo uma ribozima com domínio do tipo hammerhead, foram descritas em $S$. mansoni (Spotila et al., 1989; Ferbeyre et al., 1998). Um ribozima codificada pelo elemento denominado SmAlpha se mostrou ativa em ensaios in vitro (Ferbeyre et al., 1998; Osborne et al., 2005) e em experimentos in vivo utilizando a bactéria Thermus thermophilus para expressão heteróloga deste elemento (Vazquez-Tello et al., 2002). Tais elementos são bastante abundantes no genoma, havendo uma estimativa que até 200.000 cópias poderiam estar presentes no genoma do S. mansoni (DeMarco et al., 2004*)

* Artigo do candidato no tema. 


\section{3- Evolução da estrutura de genes de micro-exon (MEGs) em schistosomas.}

Os genes de micro exon codificam proteínas que não possuem similaridade com nenhuma proteína de organismos fora do gênero Schistosoma (DeMarco et al., 2010*) e apenas em outros platelmintos foram descritos estruturas semelhantes (Tsai et al., 2013), mas que no entanto apresentavam-se em número muito menor e com uma estrutura bem mais simples, sendo compostos por um número pequeno de micro-exons . Desta maneira é possível supor que os MEGs tem origem recente. Devido ao grande número de membros com estruturas gênicas distintas e codificando proteínas completamente diferentes é possível supor que tais genes apresentem uma evolução bastante dinâmica. Tal hipótese é reforçada pelo fato que as MEGs apresentam uma alta taxa de mutações não-sinônimas (aspecto já analisado no capítulo 1 da presente tese).

A análise de quatro genes distintos da família MEG-3 permitiu verificar que este genes encontravam-se adjacentes no genoma, fato sugestivo de serem resultantes de duplicações segmentais relativamente recentes. Além disso, uma das cópias é bastante divergente em termos de estrutura primária (25\% de identidade), mas possui uma estrutura gênica bastante semelhantes as outras cópias com a maioria dos exons conservados em termos de posição e tamanho (DeMarco et al., 2010*).

Foram observadas diferenças no número de cópias de MEGs de diferentes famílias em $S$. mansoni, S. haematobium e S. japonicum e uma análise filogenética sugere que tal diferença seja resultado de fenômenos recentes de duplicação gênica. O enriquecimento das classes de elementos de transposição Sm, SmAlpha e Perere-3 na vizinhança destes genes sugere que a inserção destes elementos pode estar associada aos eventos de duplicação detectados (Philippsen et al., 2015*). De fato, foi descrito que um evento de duplicação de um exon de 9 bp em cópias da família MEG-3 aconteceu através de um duplicação segmental de forma concomitante a inserção de um elemento SmAlpha na região intrônica (DeMarco et al., 2010*), o que sugere que tal evento de duplicação pode ter sido estimulado por um evento de quebra de dupla fita, associado a inserção do elemento transponível.

Interessantemente, o gene VAL-6 codificando uma proteína VAL (Venon-Like Antigen) possui uma estrutura mista onde os primeiros quatro exons tem estrutura bastante conservada em relação aos outros membros da mesma família, mas possui uma estrutura não conservada em outros 34 exons,

* Artigo do candidato no tema. 
sendo que muitos destes são micro-exons e sofrem splicing alternativo (Chalmers et al., 2008). Devido a semelhança da estrutura de tal região com MEGs, foi proposto que a mesma pode ter surgido a partir de um evento de recombinação que fundiu o gene VAL-6 com uma MEG (Verjovski-Almeida e DeMarco, 2011*).

\section{Considerações finais (Capitulo 3)}

O estudo de elementos de transposição em esquistossomas demonstrou um predomínio de retrotransposons, que representam uma fração considerável do genoma eque apresentam diversas famílias com alta atividade transcricional e cópias intactas. Devido a associação da atividade de transposição a uma maior dinâmica evolutiva do genoma (Oliver e Greene, 2009) é esperado que esta alta atividade transcricional reflita-se em mudanças no genoma que são propícias para um organismo parasitário que se encontra sobre grande pressão evolutiva devido a sua interação com o sistema imune dos hospedeiros.

A verificação de que ocorreu uma grande expansão no número de cópias de duas famílias e a variação no número de cópias entre isolados africanos e americanos sugerem que de fato há uma grande dinamicidade destes elementos. Exemplos da influência destes elementos na estrutura das MEGs, uma família de genes que encontra-se sobre alta pressão evolutiva, fornece um exemplo de como estes elementos podem ser importantes para a evolução do parasito.

\section{Contribuições do candidato ao tema (Capitulo 3).}

DeMarco R, Kowaltowski AT, Machado AA, Soares MB, Gargioni C, Kawano T, Rodrigues V, Madeira AM, Wilson RA, Menck CF, Setubal JC, Dias-Neto E, Leite LC, Verjovski-Almeida S. Saci$1,-2$, and -3 and Perere, four novel retrotransposons with high transcriptional activities from the human parasite Schistosoma mansoni. J Virol. 2004; 78(6):2967-78.

DeMarco R, Machado AA, Bisson-Filho AW, Verjovski-Almeida S. Identification of 18 new transcribed retrotransposons in Schistosoma mansoni. Biochem Biophys Res Commun. 2005; 333(1):230-40.

* Artigo do candidato no tema. 
DeMarco R, Venancio TM, Verjovski-Almeida S. SmTRC1, a novel Schistosoma mansoni DNA transposon, discloses new families of animal and fungi transposons belonging to the CACTA superfamily. BMC Evol Biol. 2006; 6:89.

Jacinto DS, Muniz HS, Venancio TM, Wilson RA, Verjovski-Almeida S, DeMarco R. Curupira-1 and Curupira-2, two novel Mutator-like DNA transposons from the genomes of human parasites Schistosoma mansoni and Schistosoma japonicum. Parasitology. 2011; 138(9):1124-33.

Philippsen GS, Wilson RA, DeMarco R. Accelerated evolution of schistosome genes coding for proteins located at the host-parasite interface. Genome Biol Evol. 2015; 7(2):431-43.

Venancio TM, Wilson RA, Verjovski-Almeida S, DeMarco R. Bursts of transposition from non-long terminal repeat retrotransposon families of the RTE clade in Schistosoma mansoni. Int J Parasitol. 2010; 40(6):743-9.

Verjovski-Almeida S, DeMarco R. Gene structure and splicing in schistosomes. J Proteomics. 2011; 74(9):1515-8.

\section{Referencias (Capitulo 3).}

Chalmers IW, McArdle AJ, Coulson RM, Wagner MA, Schmid R, Hirai H, Hoffmann KF. Developmentally regulated expression, alternative splicing and distinct sub-groupings in members of the Schistosoma mansoni venom allergen-like (SmVAL) gene family. BMC Genomics. 2008; 9:89.

Copeland CS, Brindley PJ, Heyers O, Michael SF, Johnston DA, Williams DL, Ivens AC, Kalinna BH. Boudicca, a retrovirus-like long terminal repeat retrotransposon from the genome of the human blood fluke Schistosoma mansoni. J Virol. 2003; 77(11):6153-66.

Copeland CS, Mann VH, Morales ME, Kalinna BH, Brindley PJ. The Sinbad retrotransposon from the genome of the human blood fluke, Schistosoma mansoni, and the distribution of related Paolike elements. BMC Evol Biol. 2005; 5:20.

Drew AC, Brindley PJ. A retrotransposon of the non-long terminal repeat class from the human blood fluke Schistosoma mansoni. Similarities to the chicken-repeat-1-like elements of vertebrates. 
Mol Biol Evol. 1997; 14(6):602-10.

Drew AC, Minchella DJ, King LT, Rollinson D, Brindley PJ. SR2 elements, non-long terminal repeat retrotransposons of the RTE-1 lineage from the human blood fluke Schistosoma mansoni. Mol Biol Evol. 1999; 16(9):1256-69.

Ferbeyre G, Smith JM, Cedergren R. Schistosome satellite DNA encodes active hammerhead ribozymes. Mol Cell Biol. 1998; 18(7):3880-8.

Feschotte C. Merlin, a new superfamily of DNA transposons identified in diverse animal genomes and related to bacterial IS1016 insertion sequences. Mol Biol Evol. 2004; 21(9):1769-80.

Feschotte C. Transposable elements and the evolution of regulatory networks. Nat Rev Genet. 2008;9(5):397-405.

Grevelding CG. Genomic instability in Schistosoma mansoni. Mol Biochem Parasitol. 1999; 101(1-2):207-16.

Hirai H, LoVerde PT. Identification of the telomeres on Schistosoma mansoni chromosomes by FISH. J Parasitol. 1996; 82(3):511-2.

Hurst GD, Werren JH. The role of selfish genetic elements in eukaryotic evolution. Nat Rev Genet. 2001; 2(8):597-606.

Laha T, Loukas A, Smyth DJ, Copeland CS, Brindley PJ. The fugitive LTR retrotransposon from the genome of the human blood fluke, Schistosoma mansoni. Int J Parasitol. 2004; 34(12):136575.

Laha T, Kewgrai N, Loukas A, Brindley PJ. Characterization of SR3 reveals abundance of nonLTR retrotransposons of the RTE clade in the genome of the human blood fluke, Schistosoma mansoni. BMC Genomics. 2005; 6:154.

Lepesant JM, Cosseau C, Boissier J, Freitag M, Portela J, Climent D, Perrin C, Zerlotini A, Grunau C. Chromatin structural changes around satellite repeats on the female sex chromosome in Schistosoma mansoni and their possible role in sex chromosome emergence. Genome Biol. 2012; 13(2):R14.

Levin HL, Moran JV. Dynamic interactions between transposable elements and their hosts. Nat Rev Genet. 2011; 12(9):615-27.

Nakayashiki H. The Trickster in the genome: contribution and control of transposable elements. Genes Cells. 2011;16(8):827-41.

Oliver KR, Greene WK. Transposable elements: powerful facilitators of evolution. Bioessays. 
2009; 31(7):703-14.

Osborne EM, Schaak JE, Derose VJ. Characterization of a native hammerhead ribozyme derived from schistosomes. RNA. 2005 Feb;11(2):187-96.

Protasio AV, Tsai IJ, Babbage A, Nichol S, Hunt M, Aslett MA, De Silva N, Velarde GS, Anderson TJ, Clark RC, Davidson C, Dillon GP, Holroyd NE, LoVerde PT, Lloyd C, McQuillan J, Oliveira G, Otto TD, Parker-Manuel SJ, Quail MA, Wilson RA, Zerlotini A, Dunne DW, Berriman M. A systematically improved high quality genome and transcriptome of the human blood fluke Schistosoma mansoni. PLoS Negl Trop Dis. 2012; 6(1):e1455.

Sinzelle L, Izsvák Z, Ivics Z. Molecular domestication of transposable elements: from detrimental parasites to useful host genes. Cell Mol Life Sci. 2009; 66(6):1073-93.

Spotila LD, Hirai H, Rekosh DM, Lo Verde PT. A retroposon-like short repetitive DNA element in the genome of the human blood fluke, Schistosoma mansoni. Chromosoma. 1989 May;97(6):421-8.

Tsai IJ, Zarowiecki M, Holroyd N, Garciarrubio A, Sanchez-Flores A, Brooks KL, Tracey A, Bobes RJ, Fragoso G, Sciutto E, Aslett M, Beasley H, Bennett HM, Cai J, Camicia F, Clark R, Cucher M, De Silva N, Day TA, Deplazes P, Estrada K, Fernández C, Holland PW, Hou J, Hu S, Huckvale T, Hung SS, Kamenetzky L, Keane JA, Kiss F, Koziol U, Lambert O, Liu K, Luo X, Luo Y, Macchiaroli N, Nichol S, Paps J, Parkinson J, Pouchkina-Stantcheva N, Riddiford N, Rosenzvit M, Salinas G, Wasmuth JD, Zamanian M, Zheng Y; Taenia solium Genome Consortium, Cai X, Soberón X, Olson PD, Laclette JP, Brehm K, Berriman M. The genomes of four tapeworm species reveal adaptations to parasitism. Nature. 2013; 496(7443):57-63.

Vazquez-Tello A, Castán P, Moreno R, Smith JM, Berenguer J, Cedergren R. Efficient transcleavage by the Schistosoma mansoni SMalpha1 hammerhead ribozyme in the extreme thermophile Thermus thermophilus. Nucleic Acids Res. 2002; 30(7):1606-12.

Wicker T, Sabot F, Hua-Van A, Bennetzen JL, Capy P, Chalhoub B, Flavell A, Leroy P, Morgante M, Panaud O, Paux E, SanMiguel P, Schulman AH. A unified classification system for eukaryotic transposable elements. Nat Rev Genet. 2007; 8(12):973-82.

Wijayawardena BK, DeWoody JA, Minchella DJ. The genomic proliferation of transposable elements in colonizing populations: Schistosoma mansoni in the new world. Genetica. 2015; 143(3):287-98. 